\title{
Dual-mobility or Constrained Liners Are More Effective Than Preoperative Bariatric Surgery in Prevention of THA Dislocation
}

\author{
Philippe Hernigou MD, Matthieu Trousselier MD, François Roubineau MD, \\ Charlie Bouthors MD, Charles Henri Flouzat Lachaniette MD
}

Published online: 29 April 2016

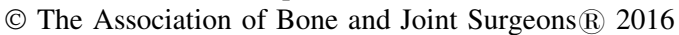

\begin{abstract}
Background Obesity is associated with an increased risk of dislocation after total hip arthroplasty (THA). However, in patients with obesity, it is not known whether the risk is only in the early postoperative period or whether it persists several years after surgery, and whether having bariatric surgery before undergoing THA and/or receiving a specific device (such as a dual-mobility or constrained acetabular liner) is more effective in terms of decreasing the risk of dislocation.

Question/purposes (1) What is the cumulative risk of dislocation in patients with obesity after THA in the absence of a dual-mobility or constrained liner, and is this related to component positioning? (2) Does bariatric
\end{abstract}

Each author certifies that he or she, or a member of his or her immediate family, has no commercial associations (eg, consultancies, stock ownership, equity interest, patent/licensing arrangements, etc) that might pose a conflict of interest in connection with the submitted article.

All ICMJE Conflict of Interest Forms for authors and Clinical Orthopaedics and Related Research ${ }^{\mathbb{R}}$ editors and board members are on file with the publication and can be viewed on request. Clinical Orthopaedics and Related Research ${ }^{\mathbb{R}}$ neither advocates nor endorses the use of any treatment, drug, or device. Readers are encouraged to always seek additional information, including FDAapproval status, of any drug or device prior to clinical use. Each author certifies that his or her institution approved the human protocol for this investigation and that all investigations were conducted in conformity with ethical principles of research.

P. Hernigou ( $₫)$, M. Trousselier, F. Roubineau, C. Bouthors,

C. H. Flouzat Lachaniette

Department of Orthopaedic Surgery, Hospital Henri Mondor, University Paris East, 94010 Creteil, France

e-mail: philippe.hernigou@wanadoo.fr surgery before undergoing THA decrease dislocation risk in patients with obesity? (3) Are dual-mobility and constrained liners efficient in preventing dislocation in patients with obesity?

Methods At our university-based practice, all surgeons adhered to the following treatment approaches: Before 2000 no dual-mobility implants or constrained liners were used for primary THAs. Between 2000 and 2008, all patients whose body mass index (BMI) was greater than $30 \mathrm{~kg} / \mathrm{m}^{2}$ received dual-mobility liners (or constrained liners), except when they had previously had bariatric surgery. After 2008, all patients with BMIs over $30 \mathrm{~kg} / \mathrm{m}^{2}$ as well as those patients who were previously treated with bariatric surgery (regardless of BMI at the time of the index THA) received dual-mobility or constrained liners. This case-control study compared the dislocation percentage between 215 hips in nonobese patients (BMI $\leq 30$ $\mathrm{kg} / \mathrm{m}^{2}$ ), 215 hips in patients with obesity (BMI $>30 \mathrm{~kg} /$ $\mathrm{m}^{2}$ ) who received standard cups, 85 hips in patients with bariatric surgery before THA using standard cups (with reduction to a BMI $<30 \mathrm{~kg} / \mathrm{m}^{2}$ ), and 155 hips in patients with obesity who received dual-mobility (when younger than 70 years) or constrained liners (when older than 70 years). All patients received the same implants except for different femoral head diameters (32-mm head with standard cups and $28-\mathrm{mm}$ head with dual-mobility or constrained liners). The patients were followed at routine intervals and were specifically queried about dislocation. All the 670 hips had a minimum followup of 5 years with a mean followup of 14 years (range 5-25 years). At the most recent followup, 101 (15\%) hips were lost to followup (respectively, 36 of 215, 34 of 215, five of 85, 24 of 155 ), which is the same ratio as observed among the underlying populations from which the patients were drawn. 
Results With standard liners, more hips in patients with BMI $>30 \mathrm{~kg} / \mathrm{m}^{2}$ dislocated than did hips in nonobese (BMI $<30 \mathrm{~kg} / \mathrm{m}^{2}$ ) patients. The cumulative number of dislocations (first time without recurrent dislocation) was 6\% (13 of 215) at 1-year followup in obese patients compared with $2 \%$ (four of 215) in nonobese patients (odds ratio [OR], 3.4; 95\% confidence interval [CI] 1.09-10.58; $\mathrm{p}=0.03$ ) and was $13 \%$ (28 of 215$)$ at 15 years followup compared with $4 \%$ (eight of 215) in nonobese patients (OR, $3.9 ; 95 \%$ CI $1.72-8.71 ; \mathrm{p}=0.001)$. When bariatric surgery was performed before THA, BMI declined from $42 \mathrm{~kg} / \mathrm{m}^{2}$ to $28 \mathrm{~kg} / \mathrm{m}^{2}$, but with the same standard liners, more hips after bariatric surgery dislocated at 1-year followup than did hips in patients with obesity without preoperative bariatric surgery (13\% [11 of 85] compared with 6\% [13 of 215]; OR, 0.43; 95\% CI 0.18-1.01; $\mathrm{p}=0.05$ ). Dual-mobility or constrained implants decreased the risk of dislocation, and fewer hips in patients with obesity with dual-mobility or constrained liners at 7 years followup had dislocated than did hips with standard liners (2\% [three of 155] compared with $9 \%$ [20 of 215]; OR, 0.19; $95 \%$ CI $0.05-0.66 ; p=0.01$ ) bringing this number in line with the number observed in nonobese subjects with standard cups. Conclusions With standard liners, the risk of dislocation is increased in patients with obesity. Preoperative decrease of BMI (with bariatric surgery) in patients with obesity did not prevent the risk of dislocation with standard liners. Use of dual-mobility or constrained liners in these patients is an effective technique to reduce the risk of postoperative hip dislocation. However, we do not yet know the full risks of loosening of dual-mobility and constrained liners in this obese population.

Level of Evidence Level III, therapeutic study.

\section{Introduction}

When obesity is defined as a body mass index (BMI) greater than $30 \mathrm{~kg} / \mathrm{m}^{2}$ in adults, obesity is recognized as an independent risk factor for postoperative hip dislocation in several studies [2, 6, 8, 15, 18, 22, 28, 35]. However, in these patients with obesity, it is not known whether the risk is only in the early postoperative period or if the risk persists several years after surgery. Biomechanical studies $[10,11,31]$ have shown that the periprosthetic soft tissues, especially large thighs, can act as moment arms (soft tissue impingement or thigh impingement) during adduction to create a laterally directed force on the femoral component and dislocation (Fig. 1). There are several options that may be discussed to reduce the risk of dislocation in patients with obesity. Bariatric surgical procedures [5] are an option for weight reduction in patients with obesity. As a result of recommendations by orthopaedic surgeons [6] for patients to lose weight before THA, bariatric surgery may be considered as an option for morbidly obese THA candidates.

However, although bariatric surgery provides substantial and sustained effects on weight loss and general complications according to some studies [19,33], these studies have not evaluated the influence of bariatric surgery before THA on the risk of dislocation. Dual-mobility acetabular cups [7, 12, 13, 34] or constrained cups [17] can decrease the risk of dislocation and may be indicated in some patients whose risk of this complication is increased. However, studies up to now have not specifically analyzed the benefit of using these implants in patients with obesity as compared with standard implants in patients with obesity.
Fig. 1 Thigh impingement (soft tissue impingement) during adduction creates a laterally directed force on the femoral component and risk of dislocation.
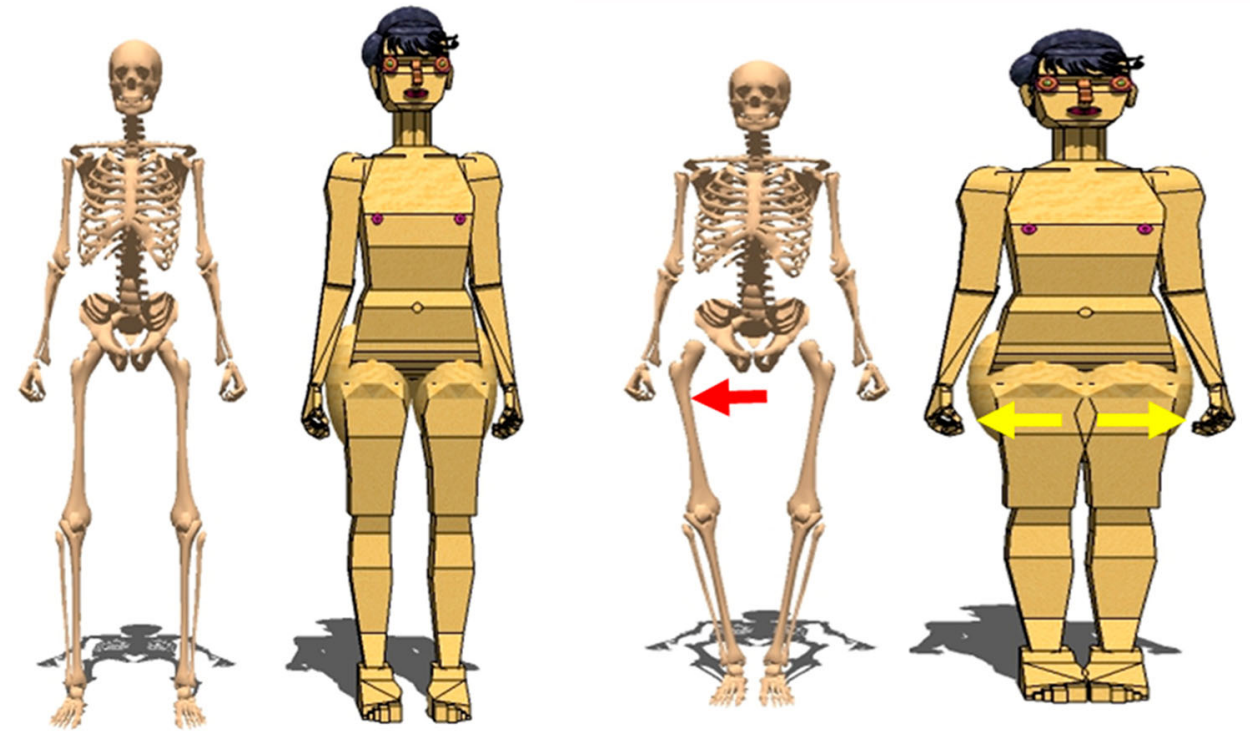
Our aim therefore was also to evaluate the prevention of risk of dislocation after THA in patients with obesity. We specifically asked: (1) What is the cumulative risk of dislocation in patients with obesity after THA in the absence of a dual-mobility or constrained liner as compared with nonobese patients, and is this related to component positioning? (2) Does bariatric surgery before undergoing THA decrease dislocation risk in patients with obesity? (3) Are dual-mobility and constrained liners efficient in patients with obesity?

\section{Patients and Methods}

This was a single-center case-control study. Between January 1990 and December 2000, we performed 430 THAs for primary osteoarthritis, dysplasia osteoarthritis, osteonecrosis, or rheumatoid arthritis of the hip (Table 1). Of those, $215(50 \%)$ were performed in patients with obesity. Of those who were treated with this approach, 35 patients $(8 \%)$ had died and $35(8 \%)$ were lost to followup, whereas 360 patients (360 hips [84\%]) were available for followup at a minimum of 15 years (median, 18 years; range 15-25 years). As a comparison, between January 2000 and December 2008, we performed 240 THAs in patients with obesity. Of this second group, 85 (35\%) were performed in patients with obesity who had undergone bariatric surgery before arthroplasty, and 155 (65\%) were performed in patients with obesity using constrained or dual-mobility liners. At our university-based practice, all surgeons adhered to the following treatment approaches: Before 2000 no dual-mobility implants or constrained liners were used for primary THAs. Between 2000 and 2008, all patients whose BMI was greater than $30 \mathrm{~kg} / \mathrm{m}^{2}$ received dual-mobility liners (or constrained liners), except when they had previously bariatric surgery, when these liners were not used in these patients. After 2008, all patients with BMIs over $30 \mathrm{~kg} / \mathrm{m}^{2}$ as well as those patients who were previously treated with bariatric surgery (regardless of BMI at the time of the index THA) received dual-mobility or constrained liners. This case-control study compared the dislocation percentage rate between 215 hips in nonobese patients (BMI $\leq 30 \mathrm{~kg} / \mathrm{m}^{2}$ ) with standard cups, 215 hips in patients with obesity $\left(\mathrm{BMI}>30 \mathrm{~kg} / \mathrm{m}^{2}\right)$ who received standard cups, 85 hips in patients with bariatric surgery before THA using standard cups (with reduction to a BMI $<30 \mathrm{~kg} / \mathrm{m}^{2}$ ), and 155 hips in patients with obesity who received dual-mobility (when younger than 70 years) or constrained liners (when older than 70 years).

Four cohorts (Fig. 2) were defined using BMI, bariatric surgery, implants (standard, dual mobility, constrained cups) as criteria of selection: Group 1 consisted of 215 THAs in patients operated on between 1990 and 2000, defined as obese (BMI $>30 \mathrm{~kg} / \mathrm{m}^{2}$ on the day of surgery), and receiving standard implants. Group 2 consisted of 215 THAs in patients operated on between 1990 and 2000 and defined as nonobese (BMI $<30 \mathrm{~kg} / \mathrm{m}^{2}$ on the day of surgery) and receiving standard implants. Demographic data were similar in all the groups (Table 1). The exact match was used for the posterior approach, type of femoral and acetabular implant, femoral head diameter (32 $\mathrm{mm}$ for all), and indication (such as primary osteoarthritis, osteonecrosis, rheumatoid arthritis, and dysplasia osteoarthritis). The closest available match was used for age and date of treatment, but up to 2 years deviation in each of these parameters was accepted. Group 3 consisted of 85 THAs performed between 2000 and 2008 in patients defined as previously obese $\left(\mathrm{BMI}>30 \mathrm{~kg} / \mathrm{m}^{2}\right)$ and having bariatric

Table 1. Demographic data and parameters of THA

\begin{tabular}{|c|c|c|c|c|c|}
\hline Characteristic & $\begin{array}{l}\text { Group } 1 \text { obese } \\
(\mathrm{n}=215 \text { hips })\end{array}$ & $\begin{array}{l}\text { Group } 2 \text { nonobese } \\
(\mathrm{n}=215 \text { hips })\end{array}$ & $\begin{array}{l}\text { Group } 3 \text { bariatric } \\
\text { surgery }(n=85 \text { hips })\end{array}$ & $\begin{array}{l}\text { Group } 4 \text { specific } \\
\text { device }(n=155 \text { hips })\end{array}$ & $\begin{array}{l}\mathrm{p} \text { value* for all } \\
\text { comparisons }\end{array}$ \\
\hline Age (years), mean \pm SD & $72 \pm 9$ & $73 \pm 11$ & $71 \pm 8$ & $72 \pm 13$ & $>0.2$ \\
\hline Gender (men/women) & $83 / 117$ & $85 / 119$ & $31 / 48$ & $53 / 89$ & $>0.2$ \\
\hline Katz-ADL score, mean \pm SD & $4.8 \pm 1.3$ & $5.2 \pm 1.3$ & $4.9 \pm 1.1$ & $5.3 \pm 1.4$ & $>0.3$ \\
\hline Parker score, mean $\pm \mathrm{SD}$ & $6.2 \pm 2.4$ & $6.5 \pm 2.3$ & $6.4 \pm 2.1$ & $6.3 \pm 2.5$ & $>0.3$ \\
\hline Primary hip osteoarthritis & 151 & 148 & 58 & 105 & $>0.4$ \\
\hline Dysplasia osteoarthritis & 18 & 20 & 8 & 17 & $>0.3$ \\
\hline Osteonecrosis & 25 & 23 & 9 & 15 & $>0.3$ \\
\hline Rheumatoid arthritis of the hip & 21 & 24 & 10 & 18 & $>0.4$ \\
\hline Cup abduction angle, mean \pm SD & $47^{\circ} \pm 9^{\circ}$ & $48^{\circ} \pm 9^{\circ}$ & $46^{\circ} \pm 11^{\circ}$ & $49^{\circ} \pm 12^{\circ}$ & $>0.3$ \\
\hline Cup anteversion angle, mean $\pm \mathrm{SD}$ & $21^{\circ} \pm 7^{\circ}$ & $20^{\circ} \pm 8^{\circ}$ & $22^{\circ} \pm 9^{\circ}$ & $20^{\circ} \pm 6^{\circ}$ & $>0.3$ \\
\hline Restauration of offset $(\mathrm{mm})$, mean $\pm \mathrm{SD}$ & $+2.2 \pm 3.3$ & $-1.3 \pm 4.1$ & $-1.1 \pm 3.6$ & $+1.8 \pm 2.9$ & $>0.4$ \\
\hline Stem anteversion, mean \pm SD & $20^{\circ} \pm 9^{\circ}$ & $19^{\circ} \pm 12^{\circ}$ & $21^{\circ} \pm 12^{\circ}$ & $18^{\circ} \pm 11^{\circ}$ & $>0.2$ \\
\hline
\end{tabular}

*Probability values for each line by comparison of two values at the same time: Groups 1 and 2, Groups 1 and 3, Groups 1 and 4, Groups 2 and 3 , etc; $\mathrm{ADL}=$ activities of daily living. 


\begin{tabular}{|c|}
\hline Group 1 \\
Obese Patients \\
BMI $>30 \mathrm{~kg} / \mathrm{m}^{2}$ \\
\hline 215 THAs \\
Standard Cup \\
32-mm Head Diameter \\
\hline
\end{tabular}
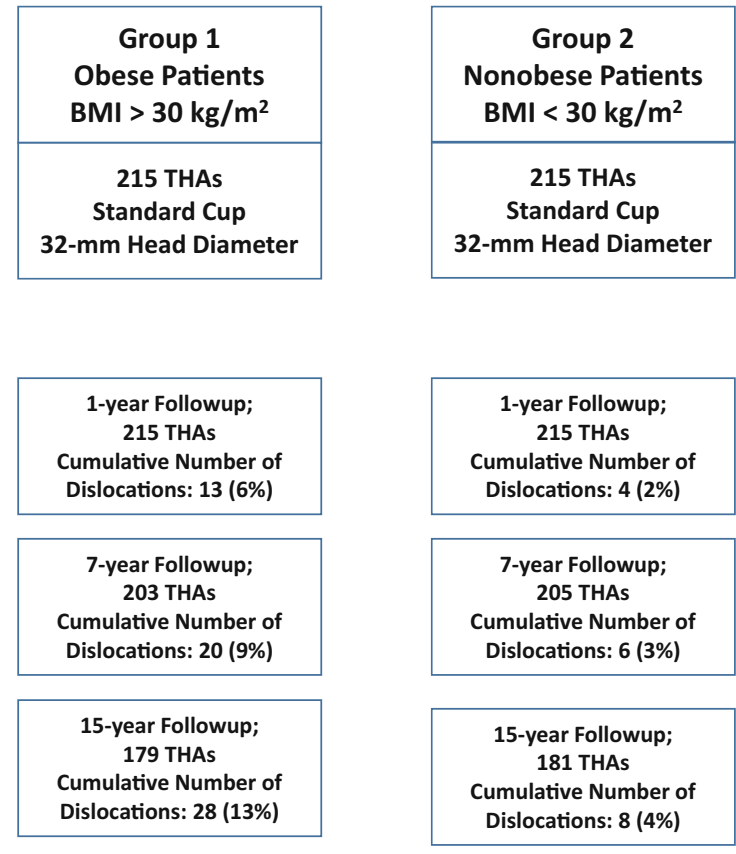

Fig. 2 Four groups were defined using BMI, bariatric surgery, implants (standard, dual mobility, constrained cups) as criteria of selection. Group 1 consisted of 215 THAs in patients with obesity $\left(\mathrm{BMI}>30 \mathrm{~kg} / \mathrm{m}^{2}\right.$ ) receiving standard implants. Group 2 consisted of 215 THAs in patients defined as nonobese (BMI $<30 \mathrm{~kg} / \mathrm{m}^{2}$ on the day of surgery) and receiving standard implants. Group 3 consisted of

surgery before THA (with reduction of BMI $<30 \mathrm{~kg} / \mathrm{m}^{2}$ on the day of surgery) and receiving standard implants; Group 4 consisted of patients with obesity who received between 2000 and 2008 dual-mobility (85 THAs) or constrained liners (70 implants) without bariatric surgery before THA $\left(\right.$ BMI $\left.>30 \mathrm{~kg} / \mathrm{m}^{2}\right)$. During the period in question, dualmobility cups were generally used when patients were younger than 70 years, and constrained liners were used when patients were older than 70 years. The four groups had similar preoperative data in terms of age, sex, etiology, and autonomy (Parker and Katz-ADL) (Table 1). Other factors known to increase the risk for THA dislocation were noted and considered as exclusion factors: history of hip surgery, excessive alcohol consumption, history of psychiatric illness requiring psychoactive medications, neurological deficit affecting the motor system (Parkinson's disease, muscle spasms after a stroke, etc), and severe cognitive dysfunction. Cancer was also an exclusion criterion as an identified risk factor for weight variation.

Patients were excluded if they had less than 5 years of followup. In Group 1 (Fig. 1) of 215 hips in patients with obesity, 15 hips (6.9\%) were lost to followup before 15 years (between 3 and 15 years), 21 (10\%) patients had died (between 4 and 15 years), and the mean followup was 18 years (range 15-25 years). In Group 2 (215 hips in nonobese patients), 20 hips (9\%) were lost to followup before 15 years (between 7 and 15 years), 14 (7\%) patients had
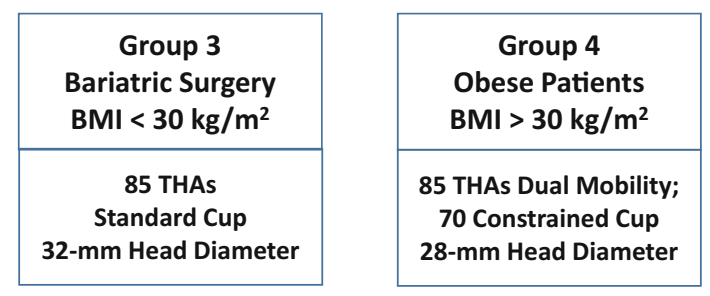
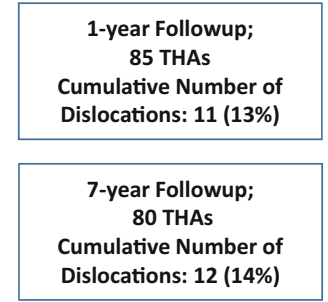

11-year Followup; 41 THAs

Cumulative Number of Dislocations: 13 (15\%)
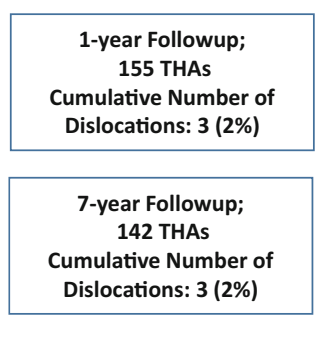

11-year Followup; 78 THAs

Cumulative Number of Dislocations: 5 (3\%)
85 THAs in patients with obesity having bariatric surgery before THA (with reduction of BMI $<30 \mathrm{~kg} / \mathrm{m}^{2}$ on the day of surgery) and receiving standard implants. Group 4 consisted of patients with obesity who received dual-mobility ( 85 THAs) or constrained liners (70 implants).

died (between 4 and 15 years), and the followup was 18 years (range 15-25 years). In Group 3 ( 85 hips in patients with obesity with preoperative bariatric surgery), four hips (5\%) were lost to followup before 15 years (between 4 and 15 years), three (4\%) patients had died (between 4 and 15 years), and the mean followup was 11 years (range 7-15 years). In Group 4 (155 hips in patients with obesity with specific implants), 10 hips (7\%) were lost to followup before 15 years (between 4 and 15 years), 14 (9\%) patients had died (between 4 and 15 years), and the followup was 12 years (range $7-15$ years).

The four groups were similar in terms of surgical approach. Surgery was performed with a posterolateral approach under general anesthesia. All the hips of Groups 1,2 , and 3 received the same implants (Ceraver Osteal, Roissy, France) with the same head diameter $(32 \mathrm{~mm})$ and a cemented standard cup. The cup diameter sizes were similar $(\mathrm{p}=0.04)$ in Groups 1,2 , and 3: mean $50.4 \mathrm{~mm}$ (range 48-58 mm) for Group 1 and mean $51.4 \mathrm{~mm}$ (range $48-58 \mathrm{~mm}$ ) for Group 2. The 32-mm alumina head was always anchored through the same Morse taper (14-16 $\mathrm{mm}$ ) on the stem (same manufacturer). Therefore, all patients had the same head-neck ratio. The femoral and acetabular components were always cemented. Patients in Group 4 received two antidislocation types of acetabular cups associated with a $28-\mathrm{mm}$ head diameter implanted on the same stems. The cemented UHMWPE constrained cup 
Table 2. Evaluation of obesity at the time of surgery in each group

\begin{tabular}{lcccc}
\hline Characteristic & $\begin{array}{c}\text { Group 1 obese } \\
(\mathrm{n}=215 \text { hips })\end{array}$ & $\begin{array}{l}\text { Group 2 nonobese } \\
(\mathrm{n}=645 \text { hips })\end{array}$ & $\begin{array}{c}\text { Group 3 bariatric } \\
\text { surgery (n=85 hips) }\end{array}$ & $\begin{array}{c}\text { Group 4 dual mobility and } \\
\text { constrained (n=155 hips) }\end{array}$ \\
\hline Weight $(\mathrm{kg})$, mean $\pm \mathrm{SD}$ & $105 \pm 14$ & $68 \pm 11$ & $75 \pm 14$ & $107 \pm 14$ \\
Height $(\mathrm{cm})$, mean $\pm \mathrm{SD}$ & $163 \pm 7$ & $164 \pm 9$ & $165 \pm 6$ & $164 \pm 8$ \\
Body mass index $\left(\mathrm{kg} / \mathrm{m}^{2}\right)$, mean $\pm \mathrm{SD}$ & $39.4 \pm 5.0$ & $25.3 \pm 3.0$ & $27.6 \pm 4.2$ & $39.9 \pm 5.4$ \\
Thigh circumference $(\mathrm{cm})$, mean $\pm \mathrm{SD}$ & $74.2 \pm 8.4$ & $54.5 \pm 6.4$ & $66.2 \pm 8.4$ & $72.2 \pm 8.4$ \\
Hip circumference $(\mathrm{cm})$, mean $\pm \mathrm{SD}$ & $123.1 \pm 8.4$ & $92.0 \pm 8.4$ & $118.4 \pm 7.8$ & $121.1 \pm 9.1$ \\
Waist circumference $(\mathrm{cm})$, mean $\pm \mathrm{SD}$ & $98.0 \pm 8.4$ & $72.2 \pm 7.4$ & $78.2 \pm 7.2$ & $97.0 \pm 9.6$ \\
\hline
\end{tabular}

(Groupe lépine, Genay, France) and dual-mobility liners (Groupe lépine, Genay, France; Ceraver Osteal) were used. No bracing or casting was performed in any patient. Because the increased risk of postoperative implant dislocation in patients who were overweight and obese may also reflect only a more difficult surgical procedure (as a result of excessive mass of adipose and muscle tissues) resulting in suboptimal orientation of the prosthetic components, the abduction angle and anteversion of the cup [38], the femoral anteversion of the stem [23], and the restoration of offset [26] were measured for each patient (Table 1).

\section{Number of Dislocations After THA}

Patients were seen routinely at 3, 6, and 12 months, then annually thereafter until the 15th year for the first two groups and until maximum followup for Groups 3 and 4. At each visit, patients were evaluated clinically and radiographically. From the charts, we determined whether there were any dislocations (posterior or anterior) or revisions for recurrent dislocation or loosening. We routinely evaluated patients, in person or by means of a standardized letter or telephone questionnaire, at 2 to 3 months postoperatively and then at each subsequent 1-year interval until rerevision or death.

At each time point, we specifically asked patients about whether they had dislocation of the hip. We did not consider a sensation of subluxation of the hip to be sufficiently specific to represent an episode of hip instability. We only considered a complete hip dislocation (the head has moved completely out of the acetabulum and required anesthesiology and surgeon intervention to relocate the hip) to be a dislocation event.

\section{Evaluation of Obesity}

Assessment of body weight and BMI (Table 2) during each medical visit was performed before THA and for THA followup at each medical visit; all persons undergo routine height and weight measurements as close as possible to the yearly anniversary dates of the index surgery. We categorized subjects as weight gainers if they gained $\geq 5 \%$ of body weight from the index date to final followup. During followup, persons who remained within $5 \%$ of their body weight at the time of surgery were classified as weight maintainers.

Patients in Group 3 who had bariatric surgery before THA were compared with those in Group 1 who did not have bariatric surgery. Patients with bariatric surgery were those who had the surgery within 2 years before THA and achieved a BMI $<30 \mathrm{~kg} / \mathrm{m}^{2}$. All yearly postsurgery weight outcomes were compared with the presurgery weight with the BMI index. Because thigh impingement is one cause of dislocation [14, 18], and because we have noted that after bariatric surgery some patients had a decrease in BMI without resolution of thigh impingement, we also measured (Fig. 3) thigh circumference and hip circumference (Table 2), which are parameters [16, 20, 25] of the body adiposity index (BAI) [3], an alternative measure of body fat. Thigh, waist, and hip circumferences were measured to the nearest $1 \mathrm{~cm}$.

\section{Statistics}

Continuous descriptive statistics used means $\pm \mathrm{SD}$ or range, percentages within groups, median values, ranges, and $95 \%$ confidence intervals (CIs) where appropriate. Qualitative data between the two groups were compared with use of the chi-square test or Fisher's exact test and quantitative data with the Mann-Whitney test. The statistical significance level was set at 0.05 .

\section{Results}

With standard liners, obesity was a risk factor for dislocation among patients treated with standard liners who were well matched in other respects (Fig. 1). The cumulative number of dislocations (first time without recurrent 


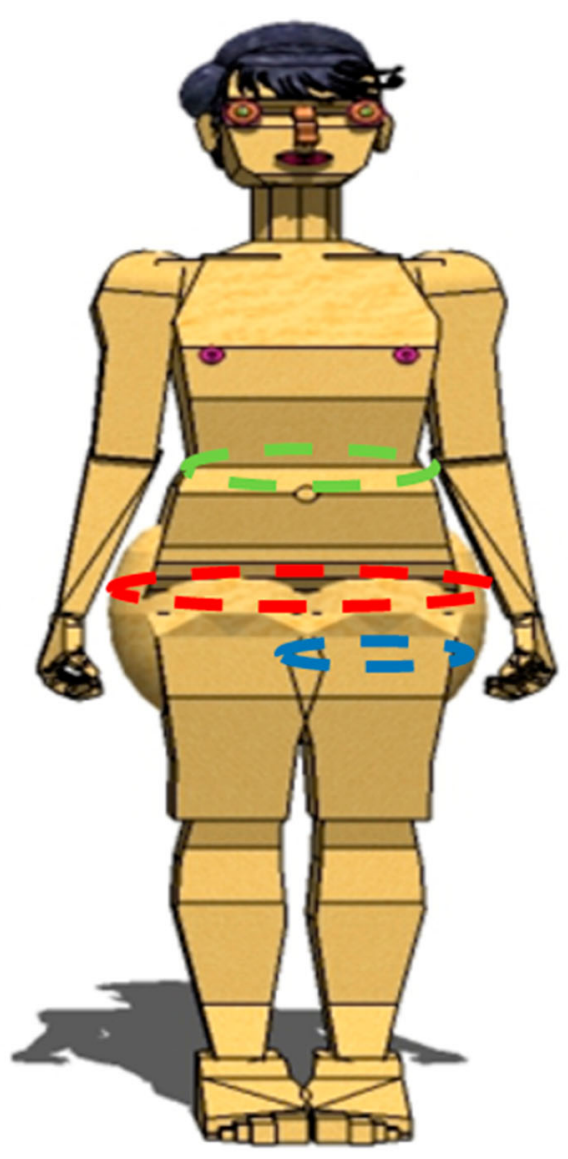

Fig. 3 Hip circumference (red) was measured as the maximum circumference at the level of the buttocks and compared with waist circumference (green) measured as the minimum circumference, in the horizontal plane, between the xiphisternum and the iliac crests. The advantage of measuring the hip circumference is that index is a direct measure of the mass of fat in the operative field, which gives an idea of the difficulty for exposure, for access to the acetabulum and correct positioning of the acetabular component. Thigh circumference (blue) also was measured directly below the gluteal fold of the thigh. It gives also an idea of thigh impingement, which occurs in our experience when thigh circumference is $>60 \mathrm{~cm}$.

dislocation) was $6 \%$ at 1-year followup (13 of 215) in patients with obesity compared with $2 \%$ (four of 215 ) in nonobese patients (odds ratio [OR], 3.4; 95\% CI 1.0910.58; $\mathrm{p}=0.03$ ). For obese patients, the risk of dislocation increased with BMI (with $1.5 \%$ per cent increase for each BMI unit above $30 \mathrm{~kg} / \mathrm{m}^{2}$; hazard ratio, $1.05 ; \mathrm{p}=0.02$ ). Despite pain relief after THA, $80 \%$ of patients with obesity gained $\geq 5 \%$ of their index body weight after surgery with a cumulative risk of dislocation at 15 years followup to $13 \%$ (28 of 215) compared with $4 \%$ (eight of 215) in nonobese patients (OR, 3.9; 95\% CI 1.72-8.71; $\mathrm{p}=0.001$ ). Female sex, hip, and thigh circumference (respectively, when $>110$ and $65 \mathrm{~cm}$ ) to BMI substantially increased predictive power for the risk of dislocation in patients with obesity; among the 15 patients in this situation, 10 had dislocations and were women with obesity. When we evaluated implant position, including offset and cup and stem position, we found no association between implant position and risk of dislocation (hazard ratio, 1.0; $p=0.76$ ) among patients with obesity as compared with nonobese patients (Table 1). In particular, the cup abduction angle was not increased in the 28 patients with obesity with dislocation $\left(46^{\circ} \pm 7^{\circ}\right)$ as compared with those who did not dislocate $\left(47^{\circ} \pm 9^{\circ}\right)$. Revision for recurrent dislocation was increased in patients with obesity as compared with nonobese patients (6\% [13 revisions among 215 hips] compared with $0.4 \%$ [one revision among 215 hips]; OR, 13.7723; 95\% CI 1.785-106.241; $\mathrm{p}=0.01$ ). Patients with obesity were no more likely to develop implant loosening than were patients without obesity (2\% [five of 215] compared with $1 \%$ [four of 215]; OR, 1.256; 95\% CI $0.333-4.742 ; \mathrm{p}=0.74$ ).

When bariatric surgery was performed before THA (Group 3), mean BMI declined from $42 \pm 7.4 \mathrm{~kg} / \mathrm{m}^{2}$ to $27.6 \pm 4.2 \mathrm{~kg} / \mathrm{m}^{2}$, but no decrease of the risk of dislocation with the numbers available was observed when Group 1 (patients with obesity) and Group 3 (bariatric surgery) were compared. With the same standard liners, more hips after bariatric surgery dislocated (Fig. 1) at 1-year followup than did hips in patients with obesity without preoperative bariatric surgery (13\% [11 of 85] compared with $6 \%$ [13 of 215]; OR, 2.309; 95\% CI 0.991-5.382; $\mathrm{p}=0.05$ ). After bariatric surgery, patients with dislocations had as much weight loss (reduction from $43.3 \pm 8.3 \mathrm{~kg} / \mathrm{m}^{2}$ to $26.9 \pm 5.4$ $\mathrm{kg} / \mathrm{m}^{2}$ ) as those without dislocation (reduction from $41.7 \pm$ $6.4 \mathrm{~kg} / \mathrm{m}^{2}$ to $28.5 \pm 4.8 \mathrm{~kg} / \mathrm{m}^{2}$ ). Interestingly, dislocations after bariatric surgery were only observed in those female patients who had no real hip or thigh circumference reduction (respectively, from 119.6 to $114.5 \mathrm{~cm}$ and from 68.2 to $66.3 \mathrm{~cm}$ ) as compared with other patients without dislocations after bariatric surgery (respectively, from 117.9 to $97.2 \mathrm{~cm}$ and from 65.9 to $59.7 \mathrm{~cm}$ ). Therefore, despite decreased BMI, these patients with dislocation presented the same technical challenges during hip arthroplasty and the same risk of thigh impingement postoperatively. With followup, the cumulative number of dislocations in the bariatric group increased from 13\% (11 dislocations) to $15 \%$ (13 dislocations) as compared with Group 1 (from $6 \%$ to $13 \%$ ) and therefore remained at 15 years followup higher than in Group 1 (Fig. 2).

Constrained or dual-mobility acetabular liners (Group 4) decreased the risk of dislocation (Fig. 1). The dislocation percentage with dual-mobility or constrained liners was not different with the numbers available in Group 4 (patients with obesity without bariatric surgery) to the percentage observed in nonobese patients of Group 2, and fewer hips at 7 years followup had dislocated with dual-mobility or constrained liners than did hips with standard liners in 
patients with obesity in Group 1 (2\% [three of 155] compared with $9 \%$ [20 of 215]; OR, 0.19; 95\% CI 0.05-0.66; p $=0.01$ ). Five patients at the maximum followup (11 years) had dislocation that occurred with these dual-mobility or constrained liners; dislocations were observed in women with high hip and thigh circumference: one (among 70 [1.4\%]) was observed with a constrained liner and four were observed (among 85 [5\%]) with dual-mobility implants $(p=0.27)$. There were no cases of revision for recurrent dislocation with constrained liners and two cases of revision for recurrent dislocation with dual-mobility liners. None of the dual-mobility or constrained cups was revised as a result of loosening.

\section{Discussion}

Obesity is becoming increasingly common; currently, more than $30 \%$ of the population in North America and nearly $15 \%$ of the population in western Europe are obese [1,37]. Given the association between BMI and development of hip osteoarthritis [1], THAs will be performed on an increasing number of patients with obesity. Of particular concern is the risk of dislocation in patients with obesity when using a posterior approach and when the BMI is greater than $35 \mathrm{~kg} / \mathrm{m}^{2}[2,6,14,18,28,35,36]$. The specific frequency and the best approaches for preventing this serious complication are unclear $[4,21,32,39]$. We therefore asked: (1) What is the cumulative risk of dislocation in patients with obesity after THA in the absence of dual-mobility or constrained liners as compared with nonobese patients? (2) Does bariatric surgery before undergoing THA decrease dislocation risk in patients with obesity? (3) Are dual-mobility and constrained liners efficient in patients with obesity?

We note several limitations to our study. First, ours was a retrospective study of a nonrandomized patient population. Second, the patient cohort limited to a center, to only one device, and one approach may limit the generalizability of the study, although we had adequate power to identify important differences among the treatment groups. Third, our measurement of stem anteversion used an old technique, and we did not analyze all the possible causes of dislocations. We also used two different implants to avoid dislocation according to the age of patients, which may be a selection bias. It is also possible that some patients who were lost may have dislocated; however, this was not likely to exert a severe bias on our results because the proportion of patients lost to followup was comparable across the four study groups. The duration of followup was different in the different groups and therefore it is possible that the surgeons' skills have improved over the 20 -year study period independently of the use of dual-mobility or constrained liners.
Obesity as a Risk Factor for Dislocation

There was a higher risk of dislocation in patients with higher BMI. This risk also has been demonstrated by other investigators [35]. Possible explanations for this finding include: extraarticular fatty tissue acting as a fulcrum [15] for dislocation and/or greater risk of suboptimal implant position because of technical difficulties associated with the procedure in patients with high BMI. However, it is not only the amount of weight that plays a role. The higher dislocation rate in women with obesity than in men with obesity can be explained by distribution of adipose tissues [22] (with gynoid obesity as opposed to android obesity). Recently, Elkins et al. [10, 11] demonstrated that morbid obesity may increase dislocation because of thigh soft tissue impingement. This is in concordance with our study that demonstrates that the effect of obesity on dislocation may be underestimated without adjustment for hip and thigh circumference. Our findings also confirm [9, 27, 29] that patients with obesity undergoing primary THA are at risk for weight gain and not for weight loss even if they are pain-free after surgery. Patients and surgeons should be made aware that weight gain risk begins within the first year and persists for at least 5 years after surgery and that the cumulative risk of dislocation increases with time.

\section{Bariatric Surgery and Hip Arthroplasty}

We chose a group of patients who according to general criteria [5] were considered candidates for bariatric surgery before the time of THA. We thereby attempted to evaluate whether bariatric surgery had decreased the risk of dislocation with better results than if they had continued with the same weight. However, a paradoxical increase of dislocation was observed as compared with those patients with obesity receiving also standard cups but without bariatric surgery before THA. This paradox could be explained by the fact that after decreased BMI, the mechanical soft tissue distortion around the hip may result in increased soft tissue laxity as a result of decreased fat around the hip. Another explanation is that bariatric surgery is followed by decreased (30-40\% of the decrease weight) muscle mass $[5,30]$, which could lead to decreased gluteus muscle mass and an increased dislocation rate in these patients. This phenomenon (paradoxical increased risk of dislocation after bariatric surgery) raises awareness that neither absolute weight nor BMI is sufficient to define whether the subsequent orthopaedic risks have been minimized. We observed that some patients (usually women) after bariatric surgery had decreased BMI without resolution of thigh impingement and without decreased hip circumference. These patients had increased risk of 
dislocation. More attention needs to be paid to the reduction of fat in the operative field rather than a simple emphasis on reduction of BMI. Importantly, this large mass of subcutaneous fat [24] can be predicted by simply measuring hip circumference, which correlates with high thigh hip circumference and of course thigh impingement. This parameter is used for calculation of the ratio of hip circumference to height known as the BAI that has been shown to be equivalent or superior to BMI as a measure of body fat [3]. This index may also appear better than BMI to predict hip dislocation in patients.

\section{Dual-mobility and Constrained Implants}

Specific implants are able to prevent dislocation and to treat repeat dislocations. Concerning obesity, Maisongrosse et al. [24] found the same dislocation rate in obese and nonobese patients $\left(\mathrm{BMI} \leq 30 \mathrm{~kg} / \mathrm{m}^{2}\right.$ ) when using in both situations dual-mobility acetabular cups, which means indirectly that with dual mobility, the rate of dislocation is reduced in the presence of obesity. We did not find any other reports using these specific implants for prevention of dislocation in patients with obesity. The prevention of dislocation with dual-mobility or constrained liners was not different in our study with the numbers available, but according to the small number of events, this needs to be confirmed by other studies. The shape and geometry of dual-mobility liners probably result in functional creation of a large-diameter articulation with extension of the coverage of the femoral head when thigh-to-thigh contact occurs. Constrained liners prevent directly the dislocation by the retention mechanism that prevents the translation of the femoral head outside the cup with thigh impingement. However, the limited followup of our series does not allow us to determine the risk of intraprosthetic dislocation of the dual-mobility implants nor to calculate the survival curve of constrained liners in these populations of patients with obesity. Other options could be discussed for reducing the risk of dislocation in patients with obesity as optimizing the head-neck ratio or increasing the head diameter, but this possibility depends on the cup diameter or increasing the femoral offset (however, offset did not appear a risk of dislocation in our series), but this could induce treatmentresistant tendinopathy.

Patients with obesity who undergo THA using standard liners are at risk of dislocation compared with patients without obesity. Preoperative decrease of BMI (with bariatric surgery) in patients with obesity did not decrease the risk of dislocation with standard liners. However, we did find that use of dual-mobility or constrained liners in these patients was an effective technique to decrease the risk of postoperative hip dislocation; however, our study did not determine in this population of patients with obesity the risks that had been described in revision arthroplasties for these implants. Orthopaedic surgeons therefore need to balance the benefits of constrained or dual-mobility cups against their specific risks (intraprosthetic dislocation and loosening), particularly for young patients. In the future, polyethylene wear should be studied in patients with obesity because of the risks of the larger mechanical loads induced by their higher body weight on these implants.

\section{References}

1. Anandacoomarasamy A, Caterson I, Sambrook P, Fransen M, March L. The impact of obesity on the musculoskeletal system. Int J Obes. 2008;32:211-222.

2. Andrew JG, Palan J, Kurup HV, Gibson P, Murray DW, Beard DJ. Obesity in total hip replacement. J Bone Joint Surg Br. 2008;90:424-429.

3. Bergman RN, Stefanovski D, Buchanan TA, Sumner AE, Reynolds JC, Sebring NG, Xiang AH, Watanabe RM. A better index of body adiposity. Obesity. 2011;19:1083-1089.

4. Berry DJ, Von Knoch M, Schleck CD, Harmsen WS. The cumulative long-term risk of dislocation after primary Charnley total hip arthroplasty. J Bone Joint Surg Am. 2004;86:9-14.

5. Buchwald H, Avidor Y, Braunwald E, Jensen MD, Pories W, Fahrbach K, Schoelles K.. Bariatric surgery: a systematic review and meta-analysis. JAMA. 2004;292:1724-1737.

6. Chee YH, Teoh KH, Sabnis BM, Ballantyne JA, Brenkel IJ. Total hip replacement in morbidly obese patients with osteoarthritis: results of a prospectively matched study. J Bone Joint Surg Br. 2010;92:1066-1071.

7. Combes A, Migaud H, Girard J, Duhamel A, Fessy MH. Low rate of dislocation of dual-mobility cups in primary total hip arthroplasty. Clin Orthop Relat Res. 2013;471:38913900.

8. Davis AM, Wood AM, Keenan AC, Brenkel IJ, Ballantyne JA. Does body mass index affect clinical outcome post-operatively and at five years after primary unilateral total hip replacement performed for osteoarthritis? A multivariate analysis of prospective data. J Bone Joint Surg Br. 2011;93:1178-1182.

9. Donovan J, Dingwall I, McChesney S. Weight change 1 year following total knee or hip arthroplasty. ANZ J Surg. 2006;76:222-225.

10. Elkins J, Daniel M, Pedersen D, Singh B, Yack H, Callaghan J, Brown T. Morbid obesity may increase dislocation in total hip patients: a biomechanical analysis. Clin Orthop Relat Res. 2013;471:971-980

11. Elkins JM, Stroud NJ, Rudert MJ, Tochigi Y, Pedersen DR, Ellis BJ, Callaghan JJ, Weiss JA, Brown TD. The capsule's contribution to total hip construct stability: a finite element analysis. $J$ Orthop Res. 2011;29:1642-1648.

12. Hamadouche M, Arnould H, Bouxin B. Is a cementless dual mobility socket in primary THA a reasonable option? Clin Orthop Relat Res. 2012;470:3048-3053.

13. Hamadouche M, Biau DJ, Huten D, Musset T, Gaucher F. The use of a cemented dual mobility socket to treat recurrent dislocation. Clin Orthop Relat Res. 2010;468:3248-3254.

14. Haverkamp D, Klinkenbijl MN, Somford MP, Albers GHR, van der Vis HM. Obesity in total hip arthroplasty: does it really matter? A meta-analysis. Acta Orthop. 2011;82:417-422.

15. Hayashi S, Nishiyama T, Fujishiro T, Hashimoto S, Kanzaki N, Nishida K, Kurosaka M. Obese patients may have more soft 
tissue impingement following primary total hip arthroplasty. Int Orthop. 2012;36:2419-2423.

16. Heitmann BL, Frederiksen P. Thigh circumference and risk of heart disease and premature death: prospective cohort study. BMJ. 2009;339:b3292.

17. Hernigou P, Filippini P, Flouzat-Lachaniette $\mathrm{CH}$, Batista SU, Poignard A. Constrained liner in neurologic or cognitively impaired patients undergoing primary THA. Clin Orthop Relat Res. 2010;468:3255-3262.

18. Kim Y, Morshed S, Joseph T, Bozic K, Ries MD. Clinical impact of obesity on stability following revision total hip arthroplasty. Clin Orthop Relat Res. 2006;453:142-146.

19. Kulkarni A, Jameson SS, James P, Woodcock S, Muller S, Reed MR. Does bariatric surgery prior to lower limb joint replacement reduce complications? Surgeon. 2011;9:18-21.

20. Lissner L, Bjorkelund C, Heitmann BL, Seidell JC, Bentsson C. Larger hip circumference independently predicts health and longevity in a Swedish female cohort. Obes Res. 2001;9:644-646.

21. Lubbeke A, Moons KG, Garavaglia G, Hoffmeyer P. Outcomes of obese and nonobese patients undergoing revision total hip arthroplasty. Arthritis Rheum. 2008;59:738-745.

22. Lubbeke A, Stern R, Garavaglia G, Zurcher L, Hoffmeyer P. Differences in outcomes of obese women and men undergoing primary total hip arthroplasty. Arthritis Rheum. 2007;57:327334.

23. Magilligan DJ. Calculation of the angle of anteversion by means of horizontal lateral roentgenography. J Bone Joint Surg Am. 1956;38:1231-1246

24. Maisongrosse P, Lepage B, Cavaignac E, Pailhe R, Reina N, Chiron P, Laffosse JM. Obesity is no longer a risk factor for dislocation after total hip arthroplasty with a double-mobility cup. Int Orthop. 2015;39:1251-1258.

25. Manolopoulos KN, Karpe F, Frayn KN. Gluteofemoral body fat as a determinant of metabolic health. Int J Obes. 2010;34:949959.

26. Matsushita A, Nakashima Y, Jingushi S, Yamamoto T, Kuraoka A, Iwamoto Y. Effects of the femoral offset and the head size on the safe range of motion in total hip arthroplasty. $J$ Arthroplasty. 2009;24:646-651.

27. McClung CD, Zahiri CA, Higa JK, Amstutz HC, Schmalzried TP. Relationship between body mass index and activity in hip or knee arthroplasty patients. J Orthop Res. 2000;18:35-39.
28. McLaughlin JR, Lee KR. The outcome of total hip replacement in obese and non-obese patients at 10- to 18-years. J Bone Joint Surg Br. 2006;88:1286-1292.

29. Middleton F, Boardman D. Total hip arthroplasty does not aid weight loss. Ann R Coll Surg Engl. 2007;89:288-291.

30. Moize V, Geliebter A, Gluck ME, Yahav E, Lorence M, Colarusso T, Drake V, Flancbaum L. Obese patients have inadequate protein intake related to protein intolerance up to 1 year following Roux-en-Y gastric bypass. Obes Surg. 2003;13:23-28.

31. Nadzadi ME, Pedersen DR, Yack HJ, Callaghan JJ, Brown TD. Kinematics, kinetics, and finite element analysis of common place maneuvers at risk for total hip dislocation. $J$ Biomech. 2003;36:577-591.

32. Paans N, Stevens M, Wagenmakers R, van Beveren J, van der Meer K, Bulstra S, van den Akker-Scheek I. Changes in bodyweight after total hip arthroplasty: short-term and long-term effects. Phys Ther. 2012;92:680-687.

33. Parvizi J, Trousdale RT, Sarr MG. Total joint arthroplasty in patients surgically treated for morbid obesity. J Arthroplasty. 2000;15:1003-1008.

34. Philippot R, Camilleri JP, Boyer B, Adam P, Farizon F. The use of a dual-articulation acetabular cup system to prevent dislocation after primary total hip arthroplasty: analysis of 384 cases at a mean follow-up of 15 years. Int Orthop. 2009;33:927-932.

35. Sadr Azodi O, Adami J, Lindstrom D, Eriksson K, Wladis A, Bellocco R. High body mass index is associated with increased risk of implant dislocation following primary total hip replacement: 2,106 patients followed for up to 8 years. Acta Orthop. 2008;79:141-147.

36. Sanchez-Sotelo J, Berry D. Epidemiology of instability after total hip replacement. Orthop Clin North Am. 2001;32:543-552.

37. Sturm R. Increases in morbid obesity in the USA: 2000-2005. Public Health. 2007;121:492-496.

38. Widmer KH. A simplified method to determine acetabular cup anteversion from plain radiographs. J Arthroplasty. 2004;19:387390.

39. Zhu S, Heo M, Plankey M, Faith MS, Allison DB. Associations of body mass index and anthropometric indicators of fat mass and fat free mass with all-cause mortality among women in the first and second national health and nutrition examination surveys follow-up studies. Ann Epidemiol. 2003;13:286-293. 